\title{
Prognostic Impact of Postoperative Complications in High-Risk Operable Non-small Cell Lung Cancer
}

\author{
Seungwook Lee, M.D., Md Roknuggaman, M.B.B.S., M.Sc., Jung A Son, M.D., Seungji Hyun, M.D., Joonho Jung, \\ M.D., Seokjin Haam, M.D., Ph.D., Woo Sik Yu, M.D. \\ Department of Thoracic and Cardiovascular Surgery, Ajou University School of Medicine, Suwon, Korea
}

\author{
ARTICLE INFO \\ Received September 3, 2021 \\ Revised October 20, 2021 \\ Accepted November 6, 2021 \\ Corresponding author \\ Woo Sik Yu \\ Tel 82-31-219-4214 \\ Fax 82-31-219-5215 \\ E-mail yws081011@aumc.ac.kr \\ ORCID \\ https://orcid.org/0000-0002-5100-9131 \\ This study was presented at the 51st \\ Annual Meeting of the Korean Society \\ for Thoracic and Cardiovascular Surgery \\ (KTCVS) in Siheung, Korea, November \\ $5-7,2020$.
}

\begin{abstract}
Background: Patients with high-risk (HR) operable non-small cell lung cancer (NSCLC) may have unique prognostic factors. This study aimed to evaluate surgical outcomes in $\mathrm{HR}$ patients and to investigate prognostic factors in HR patients versus standard-risk (SR) patients.

Methods: In total, 471 consecutive patients who underwent curative lung resection for NSCLC between January 2012 and December 2017 were identified and reviewed retrospectively. Patients were classified into HR $(n=77)$ and SR $(n=394)$ groups according to the American College of Surgeons Oncology Group criteria (Z4099 trial). Postoperative complications were defined as those of grade 2 or higher by the Clavien-Dindo classification. Results: The HR group comprised more men and older patients, had poorer lung function, and had more comorbidities than the SR group. The patients in the HR group also experienced more postoperative complications ( $p \leq 0.001)$. More HR patients died without disease recurrence. The postoperative complication rate was the only significant prognostic factor in multivariable Cox regression analysis for HR patients but not SR patients. HR patients without postoperative complications had a survival rate similar to that of SR patients. Conclusion: The overall postoperative survival of HR patients with NSCLC was more strongly affected by postoperative complications than by any other prognostic factor. Care should be taken to minimize postoperative complications, especially in HR patients.
\end{abstract}

Keywords: Lung neoplasms, Non-small-cell lung carcinoma, Postoperative care, Prognosis, Surgery

\section{Introduction}

Lung cancer is the leading cause of cancer-related death in Korea and worldwide [1,2]. Non-small cell lung cancer (NSCLC) accounts for approximately $85 \%$ of lung cancers [3]. Surgery is the mainstay of treatment for early-stage NSCLC, and lobectomy has been accepted as the standard treatment. Sublobar resection, such as segmentectomy or wedge resection, is recommended in selected patients with poor pulmonary reserve or other major comorbidities and in those with smaller tumors [4].

The pathologic tumor-node-metastasis (TNM) stage is known to be the most important prognostic factor for surgically treated patients with NSCLC [5]. However, patient comorbidities are also important prognostic factors for survival [6-8]. Age and smoking are strongly associated with comorbidities such as chronic obstructive pulmonary disease and cardiovascular disease, which commonly coexist with NSCLC [9]. These comorbidities may have independent negative impacts on survival, and they also influence the outcomes of NSCLC treatment such as surgery or adjuvant therapy. Therefore, the presence of several comorbidities may have a greater impact than the cancer stage on the prognosis of high-risk (HR) patients with NSCLC.

Because cardiopulmonary assessments such as pulmonary function tests or exercise tests, are closely related to postoperative outcomes, these evaluations are essential in selecting appropriate treatments for HR patients with early-stage NSCLC [10]. Although algorithms exist for determining the risk associated with lung resection, the identifi- 
cation of patients for whom lobectomy poses a HR is complicated and remains a clinical decision $[10,11]$. Due to advances in surgical and anesthetic techniques, such as

\begin{tabular}{|c|l|}
\hline High-risk criteria & Standard-risk criteria \\
\hline - Meet $\geq 1$ major criteria & $\cdot$ No major criteria met \\
- FEV $1 \leq 50 \%$ predicted & $\cdot$ Meet $\leq 1$ minor criteria \\
- DLCO $\leq 50 \%$ predicted & \\
- Meets $\geq 2$ minor criteria & \\
- Age $\geq 75 \mathrm{yr}$ & \\
- FEV $151 \%-60 \%$ predicted & \\
- DLCO $51 \%-60 \%$ predicted & \\
- RVSP $\geq 40 \mathrm{~mm} \mathrm{Hg}$ & \\
- LVEF $\leq 40 \%$ & \\
- Exercise $\mathrm{SpO}_{2} \leq 88 \%$ & \\
\hline
\end{tabular}

Fig. 1. Schema of high-risk criteria from the American College of Surgeons Oncology Group (ACOSOG) Z4099 trial. FEV1, forced expiratory volume in 1 second; DLCO, diffusing capacity of lung for carbon monxide; RVSP, right ventricular systolic pressure; LVEF, left ventricular ejection fraction; $\mathrm{SpO}_{2}$, oxygen saturation. minimally invasive techniques, lobectomy may be performed safely with acceptable outcomes in some HR patients [12]. This study aimed to investigate the surgical outcomes of HR patients who underwent surgical treatment for NSCLC and to identify prognostic factors in these patients.

\section{Methods}

\section{Patients}

This retrospective study was approved by the Institutional Review Board of Ajou University School of Medicine (approval no., AJIRB-MED-MDB-21-216), and the need for informed consent was waived. By reviewing electronic medical records, we identified patients with NSCLC who underwent curative lung resection between January 2012 and December 2017. Patients who had a history of lung

Table 1. Baseline characteristics

\begin{tabular}{|c|c|c|c|c|}
\hline Characteristic & Total $(n=471)$ & $\mathrm{HR}(\mathrm{n}=77)$ & SR $(n=394)$ & $\mathrm{p}$-value \\
\hline Age (yr) & $64.09 \pm 9.9$ & $72.6 \pm 7.0$ & $62.4 \pm 9.6$ & $<0.001$ \\
\hline Sex & & & & 0.001 \\
\hline Male & $304(64.5)$ & $63(81.8)$ & $241(61.2)$ & \\
\hline Female & $167(35.5)$ & $14(18.2)$ & $153(38.8)$ & \\
\hline Smoking & & & & 0.017 \\
\hline Nonsmoker & $252(53.5)$ & $31(40.3)$ & $221(56.1)$ & \\
\hline Ex-smoker & $131(27.8)$ & $31(40.3)$ & $100(25.4)$ & \\
\hline Current smoker & 88 (18.6) & $15(19.5)$ & 73 (18.5) & \\
\hline Age-adjusted CCI & $3.0(2.0-4.0)$ & $4.0(2.0-7.0)$ & $3.0(0.0-5.0)$ & $<0.001$ \\
\hline FEV1 (\% predicted) & $91.51 \pm 16.9$ & $80.2 \pm 20.2$ & $93.8 \pm 15.2$ & $<0.001$ \\
\hline DLCO (\% predicted) & $74.85 \pm 21.0$ & $47.7 \pm 12.8$ & $80.4 \pm 17.8$ & $<0.001$ \\
\hline Approach & & & & 0.073 \\
\hline VATS & $305(64.7)$ & $43(55.8)$ & $262(66.5)$ & \\
\hline Thoracotomy & $166(35.3)$ & $34(44.2)$ & $132(33.5)$ & \\
\hline Operation & & & & 0.089 \\
\hline Sublobar resection & 61 (12.9) & $15(19.5)$ & $46(11.7)$ & \\
\hline Lobectomy & $379(80.5)$ & $55(71.4)$ & $324(82.2)$ & \\
\hline Extended resection & $31(6.6)$ & $7(9.1)$ & $24(6.1)$ & \\
\hline Pathology & & & & $<0.001$ \\
\hline $\mathrm{SqCC}$ & $132(28.1)$ & $42(54.5)$ & $90(22.8)$ & \\
\hline Adenocarcinoma & $314(66.6)$ & $32(41.6)$ & $282(71.6)$ & \\
\hline Other NSCLC & $25(5.3)$ & $3(3.9)$ & $22(5.6)$ & \\
\hline Pathologic stage & & & & 0.470 \\
\hline I & $298(63.2)$ & $44(57.1)$ & $254(64.5)$ & \\
\hline II & $91(19.3)$ & $17(22.1)$ & $74(18.8)$ & \\
\hline III & $82(16.1)$ & $16(20.8)$ & $66(16.8)$ & \\
\hline Adjuvant treatment & $137(49.4)$ & $14(18.2)$ & $123(31.2)$ & 0.030 \\
\hline
\end{tabular}

Values are presented as mean \pm standard deviation, number $(\%)$, or median (interquartile range), unless otherwise stated.

$\mathrm{HR}$, high-risk patient; SR, standard-risk patient; CCI, Charlson comorbidity index; FEV1, forced expiratory volume in 1 second; DLCO, diffusing capacity of lung for carbon monoxide; VATS, video-assisted thoracoscopic surgery; SqCC, squamous cell carcinoma; NSCLC, non-small cell lung cancer. 
cancer or previously received neoadjuvant treatment were excluded. We identified 471 patients who met the inclusion criteria, and classified them into $\operatorname{HR}(n=77)$ and stan- dard-risk (SR) groups $(\mathrm{n}=394)$ according to the American College of Surgeons Oncology Group (ACOSOG) criteria (Z4099 trial) (Fig. 1) [13]. The ACOSOG Z4099 trial was a

Table 2. Postoperative morbidity and mortality

\begin{tabular}{|c|c|c|c|c|}
\hline Variable & Total $(n=471)$ & $\operatorname{HR}(n=77)$ & $S R(n=394)$ & $p$-value \\
\hline Any complication & $123(26.1)$ & $39(50.6)$ & $84(21.3)$ & $<0.001$ \\
\hline Pulmonary complication & $104(22.1)$ & $37(48.1)$ & $67(17.0)$ & $<0.001$ \\
\hline Pneumonia & $49(10.4)$ & $24(31.2)$ & $25(6.3)$ & $<0.001$ \\
\hline Prolonged air leakage & $54(11.5)$ & $14(18.2)$ & $40(10.2)$ & 0.039 \\
\hline Pleural effusion & $5(1.1)$ & $3(3.9)$ & $2(0.5)$ & 0.033 \\
\hline Bleeding & $8(1.7)$ & $2(2.6)$ & $6(1.5)$ & 0.853 \\
\hline Chylothorax & $3(0.8)$ & 0 & $3(0.8)$ & 1.000 \\
\hline Arrhythmia & $13(2.7)$ & $3(3.9)$ & $10(2.5)$ & 0.776 \\
\hline Cerebrovascular accident & $2(0.5)$ & 0 & $2(0.5)$ & 1.000 \\
\hline Hospital stay (day) & $10.4 \pm 10.5$ & $16.4 \pm 16.6$ & $9.2 \pm 8.4$ & $<0.001$ \\
\hline 30-day mortality & $8(1.6)$ & $3(3.9)$ & $5(1.3)$ & $<0.001$ \\
\hline 90-day mortality & $16(3.3)$ & $8(10.4)$ & $8(2.1)$ & $<0.001$ \\
\hline
\end{tabular}

Values are presented as number (\%) or mean \pm standard deviation.

$\mathrm{HR}$, high-risk patient; SR, standard-risk patient.

A

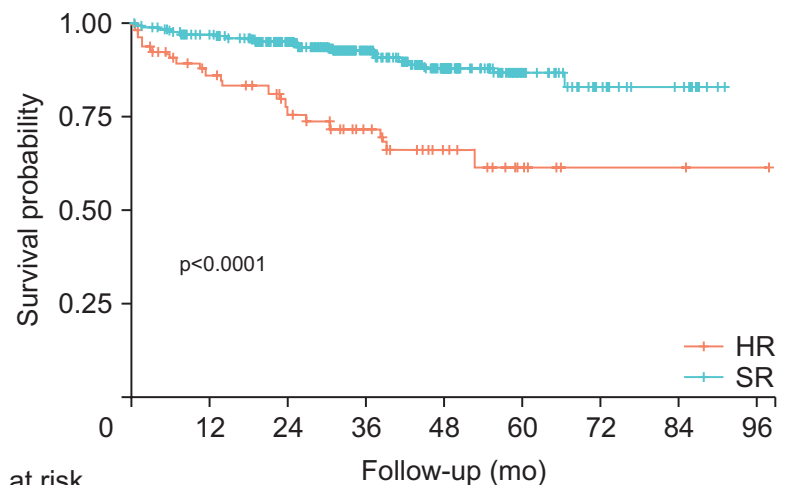

No. at risk

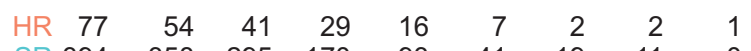

C

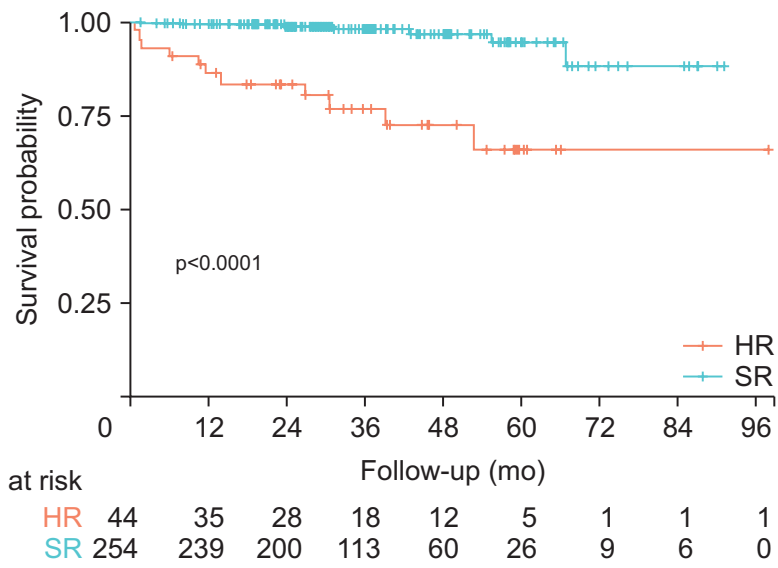

B

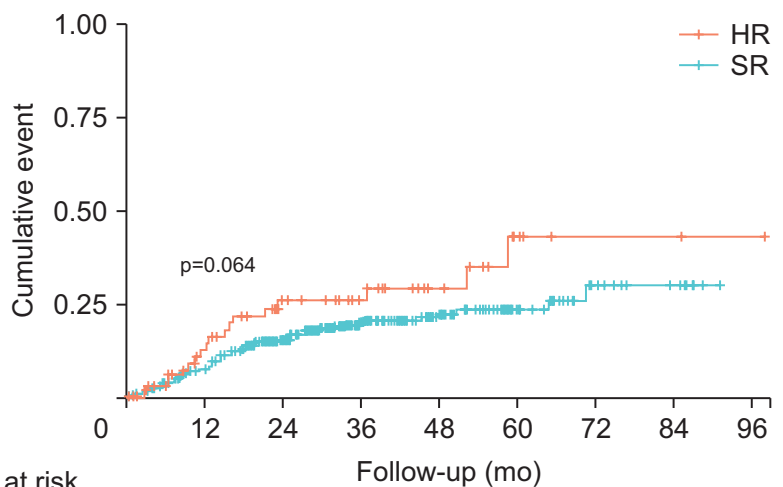

No. at risk
D

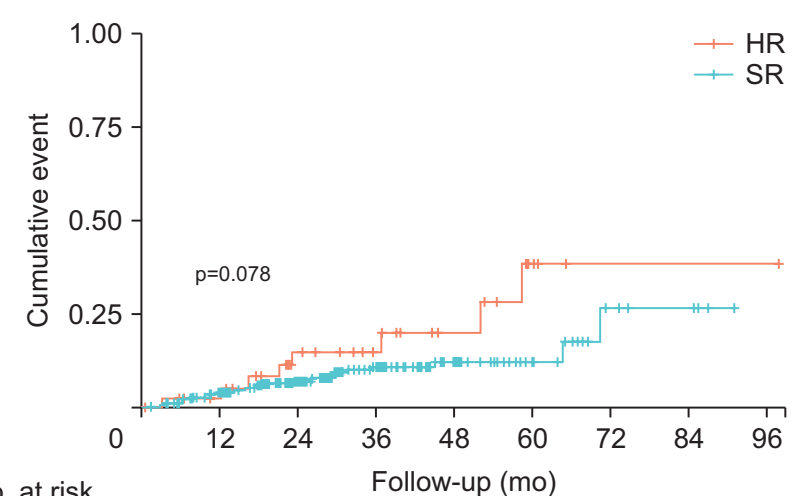

No. at risk

\begin{tabular}{|c|c|c|c|c|c|c|}
\hline $\begin{array}{l}\text { HR } 44 \\
\text { SR } 254\end{array}$ & $\begin{array}{r}35 \\
232\end{array}$ & $\begin{array}{r}24 \\
188\end{array}$ & $\begin{array}{r}16 \\
106\end{array}$ & $\begin{array}{l}10 \\
54\end{array}$ & $\begin{array}{r}4 \\
22\end{array}$ & 1 \\
\hline
\end{tabular}

Fig. 2. Comparison of overall survival and cumulative incidence of recurrence. (A) Overall survival in all patients by risk. (B) Cumulative incidence of recurrence in all patients by risk. Overall survival of $(C)$ stage 1 lung cancer patients, (E) stage 2 lung cancer patients, and (G) stage 3 lung cancer patients. Cumulative incidence of recurrence in (D) stage 1 lung cancer patients, (F) stage 2 lung cancer patients, and $(\mathrm{H})$ stage 3 lung cancer patients. HR, high-risk; SR, standard-risk. (Continued on next page). 
$E$

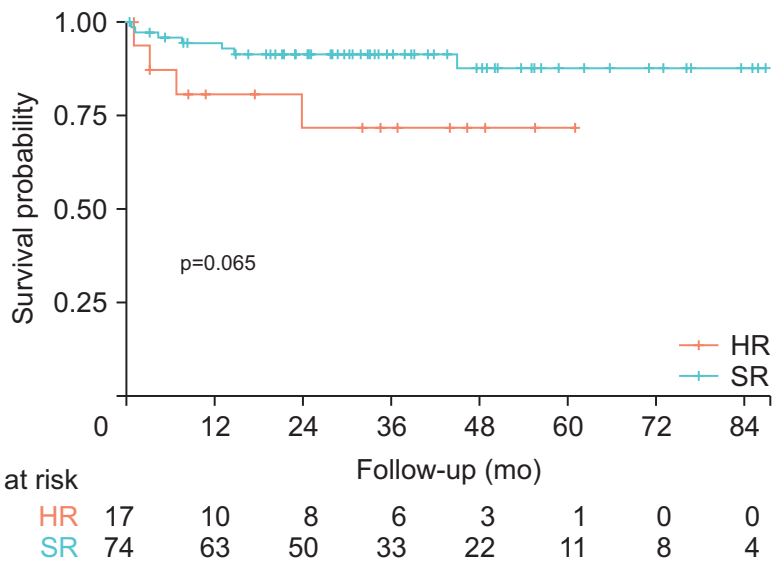

G

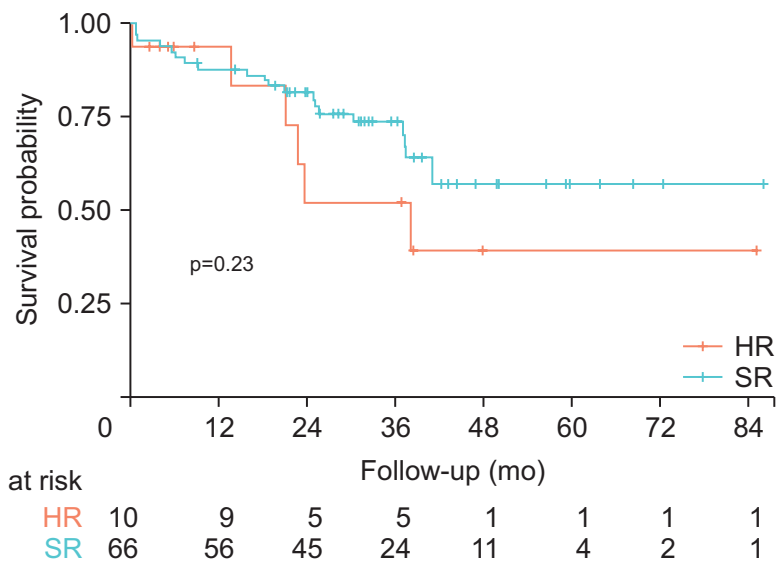

Fig. 2. (Continued; caption shown on previous page).

randomized study of sublobar resection versus stereotactic body radiation therapy (SBRT) for HR stage I NSCLC. Patients were categorized as HR when they met more than 1 major enrollment criterion (preoperative forced expiratory volume in 1 second [FEV1] or diffusing capacity for carbon monoxide [DLCO] $<50 \%$ of the predicted value) or 2 minor criteria (age, $\geq 75$ years; pulmonary hypertension, ejection fraction $\leq 40 \%$; or exercise partial pressure of oxygen $\leq 55$ $\mathrm{mm} \mathrm{Hg}$ or oxygen saturation $\leq 88 \%$ ).

\section{Data collection}

Patients' demographic and clinical characteristics included age, sex, smoking status, age-adjusted Charlson comorbidity index (CCI) [14], pulmonary function, echocardiography findings, tumor histology, pathological stage, type of surgery, and history of adjuvant therapy. Pathological staging was determined using the eighth edition of the TNM classification [15]. The extent of surgery was classified as sublobar resection, lobectomy, or extended resection, which included bilobectomy and pneumonectomy.
$F$

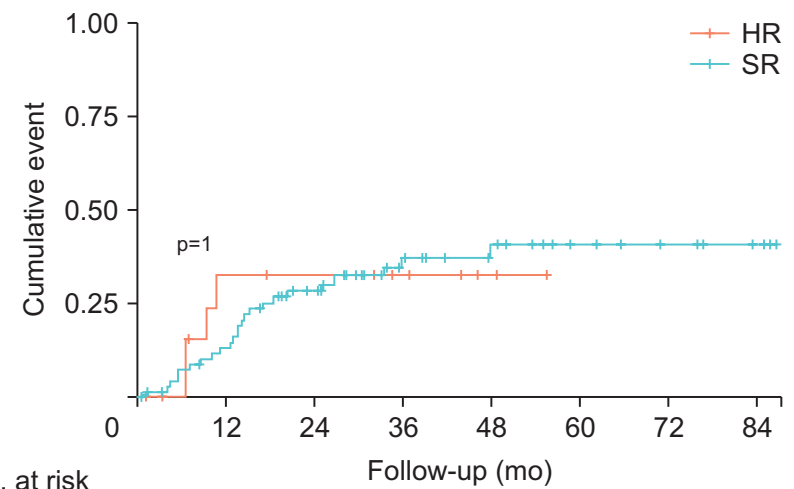

No. at risk

$\begin{array}{rrrrrrrrr}\mathrm{HR} & 17 & 8 & 7 & 5 & 2 & 0 & 0 & 0 \\ \mathrm{SR} & 74 & 58 & 40 & 24 & 17 & 10 & 7 & 4\end{array}$

$\mathrm{H}$

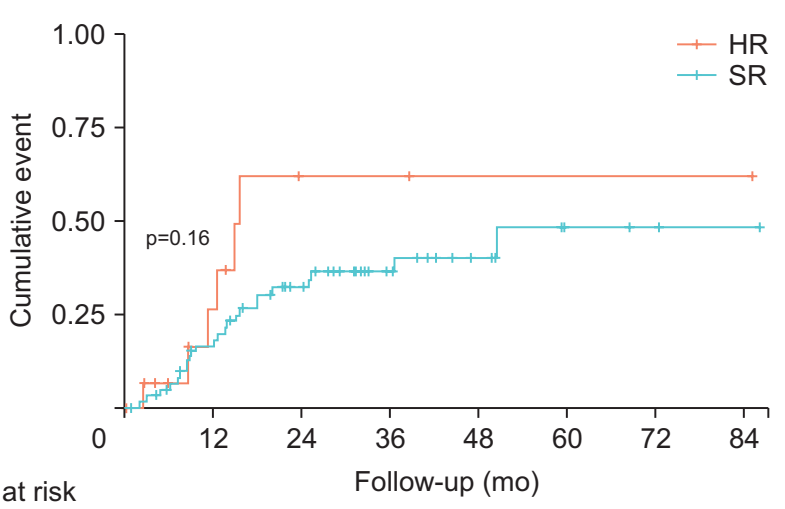

No. at risk

$\begin{array}{rrrrrrrrr}\mathrm{HR} & 16 & 7 & 2 & 2 & 1 & 1 & 1 & 1 \\ \mathrm{SR} & 66 & 49 & 33 & 18 & 10 & 3 & 2 & 1\end{array}$

Postoperative complications (PCs) were defined as those of grade 2 or higher, according to the Clavien-Dindo classification, that occurred during hospitalization or readmission up to and including 30 days postoperatively [16].

\section{Statistical analyses}

Continuous variables were compared using the Student t-test or the Mann-Whitney U-test. Categorical variables were compared using the chi-square test or the Fisher exact test. Survival and cumulative incidence of recurrence by risk group were analyzed using Kaplan-Meier curves, and comparisons were made using the log-rank test. Univariable and multivariable analyses were conducted using a Cox proportional hazards regression model to identify prognostic factors that may affect survival. Risk factors for PCs were analyzed using binary logistic regression. Variables with a $p$-value $\leq 0.1$ were included in the multivariable analyses. A p-value $\leq 0.05$ was considered to indicate statistical significance. Statistical analyses were performed using IBM SPSS ver. 25.0 (IBM Corp., Armonk, NY, USA) 
and R ver. 4.1.0 (The R Foundation for Statistical Computing, Vienna, Austria; https://www.r-project.org/).

\section{Results}

\section{Baseline characteristics}

The baseline characteristics of the 471 patients included in the study are described in Table 1 . The mean \pm standard deviation age of patients was $64.09 \pm 9.9$ years, and 304 (64.5\%) were men. The HR group was older, had a higher proportion of men, had more patients with a history of smoking, had higher CCI scores, and had lower FEV1 and DLCO than the SR group. Adenocarcinoma was the most common overall histological type in all study patients; however, squamous cell carcinoma (SqCC) was the predominant histology observed in the HR group. The HR group underwent more thoracotomies and sublobar resections, but without statistically significant differences from the SR group. Although there was no significant difference in pathologic stage between the groups, fewer adjuvant treatments were performed in the HR group.

\section{Postoperative morbidity and mortality}

A higher proportion of patients experienced PCs in the HR group than in the SR group (HR group, 50.6\% versus SR group, 21.3\%). Pneumonia was the most frequent complication in HR patients, and its incidence was significantly higher than that in SR patients $(\mathrm{p}<0.001)$. In contrast, persistent air leakage was the most common complication in SR patients. Hospital stays were significantly longer in the HR group than in the SR group $(\mathrm{p}<0.001)$. The 30 - and $90-$ day mortality rates were higher in the HR group than in the SR group $(\mathrm{p}<0.001)$ (Table 2$)$.

\section{Comparison of overall survival and cumulative incidence of recurrence}

The overall survival of HR patients was significantly

Table 3. Prognostic factors for overall survival using a Cox regression model in all patients

\begin{tabular}{|c|c|c|c|c|}
\hline \multirow{2}{*}{ Variable } & \multicolumn{2}{|c|}{ Univariable } & \multicolumn{2}{|c|}{ Multivariable } \\
\hline & Hazard ratio $(95 \% \mathrm{Cl})$ & $p$-value & Hazard ratio $(95 \% \mathrm{Cl})$ & p-value \\
\hline Age $(y r)$ & $1.040(1.011-1.071)$ & 0.008 & $0.982(0.942-1.025)$ & 0.408 \\
\hline Female (vs. male) & $0.359(0.181-0.712)$ & 0.003 & $0.718(0.347-1.484)$ & 0.371 \\
\hline \multicolumn{5}{|l|}{ Smoking } \\
\hline Nonsmoker & 1 & & - & \\
\hline Ex-smoker & $1.401(0.768-2.556)$ & 0.272 & - & \\
\hline Current smoker & $1.484(0.748-2.943)$ & 0.259 & - & \\
\hline FEV1 (\% predicted) & $0.973(0.959-0.988)$ & $<0.001$ & - & \\
\hline DLCO (\% predicted) & $0.958(0.944-0.973)$ & $<0.001$ & $0.970(0.946-0.994)$ & 0.015 \\
\hline Age-adjusted CCI & $1.201(1.035-1.394)$ & 0.016 & $1.131(0.900-1.421)$ & 0.289 \\
\hline VATS (vs. open) & $0.406(0.237-0.696)$ & 0.001 & $0.824(0.455-1.492)$ & 0.523 \\
\hline \multicolumn{5}{|l|}{ Operation } \\
\hline Sublobar resection & 1 & & 1 & \\
\hline Lobectomy & $0.977(0.419-2.330)$ & 0.977 & $0.485(0.191-1.232)$ & 0.128 \\
\hline Extended resection & $0.017(1.250-9.491)$ & 0.017 & $0.836(0.258-2.715)$ & 0.766 \\
\hline \multicolumn{5}{|l|}{ Histology } \\
\hline $\mathrm{SqCC}$ & 1 & & 1 & \\
\hline Adenocarcinoma & $0.252(0.146-0.434)$ & $<0.001$ & $0.686(0.349-1.348)$ & 0.274 \\
\hline Other NSCLC & $0.256(0.061-1.068)$ & 0.062 & $0.616(0.134-2.836)$ & 0.534 \\
\hline \multicolumn{5}{|l|}{ Pathologic stage } \\
\hline I & 1 & & 1 & \\
\hline II & $2.110(0.996-4.471)$ & 0.051 & $1.589(0.704-3.586)$ & 0.265 \\
\hline III & $6.401(3.524-11.630)$ & $<0.001$ & $7.956(3.528-17.940)$ & $<0.001$ \\
\hline Postoperative complication & $3.776(2.232-6.386)$ & $<0.001$ & $3.090(1.733-5.509)$ & $<0.001$ \\
\hline HR (vs. SR) & $0.274(0.160-0.472)$ & $<0.001$ & $1.112(0.484-2.553)$ & 0.803 \\
\hline Adjuvant treatment & $1.675(0.978-2.868)$ & 0.060 & $0.595(0.283-1.250)$ & 0.171 \\
\hline
\end{tabular}

$\mathrm{Cl}$, confidence interval; FEV1, forced expiratory volume in 1 second; DLCO, diffusing capacity of lung for carbon monoxide; CCI, Charlson comorbidity index; VATS, video-assisted thoracoscopic surgery; SqCC, squamous cell carcinoma; NSCLC, non-small cell lung cancer; HR, high-risk patient; SR, standard-risk patient. 
worse than that of SR patients ( $\mathrm{p} \leq 0.001)$. Three- and 5 -year survival rates of SR patients were $92.5 \%$ and $86.3 \%$, respectively, and those of HR patients were $71.8 \%$ and $61.4 \%$, respectively (Fig. 2A). HR patients seemed to have a higher recurrence; however, the difference was not statistically significant ( $\mathrm{p}=0.064)$ (Fig. 2B).

\section{Prognostic factors for overall survival using a Cox regression model}

Prognostic factors for overall survival were investigated using Cox regression analysis in the entire cohort (Table 3). In the univariable analysis, age, sex, FEV1, DLCO, CCI, surgical technique, operation extent, tumor histology and pathologic stage, PCs, risk group, and history of adjuvant treatment were significantly associated with overall survival. Variables with p-values $<0.1$ were included in the multivariable analysis to exclude confounding factors. Since FEV1 and DLCO were strongly correlated (Pearson correlation coefficient of $0.396 ; p \leq 0.001$ ), only DLCO was included in the multivariate analysis. DLCO, pathologic stage, and PCs were revealed as independent significant prognostic factors for overall survival (Table 3). We also performed subgroup analyses in the HR and SR groups. Pathologic stage was a significant prognostic factor in SR patients (Table 4), while PCs were a significant prognostic factor in HR patients (Table 5).

\section{Overall survival and cumulative incidence of recurrence in accordance with risk group and postoperative complication}

Patients with PCs had significantly poorer overall longterm survival than those without PCs in both groups (SR, $\mathrm{p}=0.018 ; \mathrm{HR}, \mathrm{p}=0.001)$. HR patients without complications showed comparable survival to SR patients with or without complications ( $\mathrm{p}=0.502$ and $\mathrm{p}=0.458$, respectively). However, HR patients with complications had significantly poorer survival than SR patients with or without complications ( $\mathrm{p} \leq 0.001)$ (Fig. 3A). HR patients without PCs had a higher recurrence rate than SR patients without PCs $(\mathrm{p}=0.014)$. However, there were no significant differences

Table 4. Prognostic factors for overall survival using a Cox regression model in standard-risk patients

\begin{tabular}{|c|c|c|c|c|}
\hline \multirow{2}{*}{ Variable } & \multicolumn{2}{|c|}{ Univariable } & \multicolumn{2}{|c|}{ Multivariable } \\
\hline & Hazard ratio $(95 \% \mathrm{Cl})$ & $\mathrm{p}$-value & Hazard ratio $(95 \% \mathrm{Cl})$ & $p$-value \\
\hline Age $(y r)$ & $1.037(0.999-1.077)$ & 0.058 & 1.007 (0.962-1.054) & 0.765 \\
\hline Female (vs. male) & $0.517(0.242-1.104)$ & 0.088 & $0.874(0.397-2.096)$ & 0.749 \\
\hline \multicolumn{5}{|l|}{ Smoking } \\
\hline Nonsmoker & 1 & & - & \\
\hline Ex-smoker & $0.460(0.208-1.015)$ & 0.055 & - & \\
\hline Current smoker & $0.595(0.241-1.466)$ & 0.259 & - & \\
\hline FEV1 (\% predicted) & $0.968(0.946-0.990)$ & 0.005 & - & \\
\hline DLCO (\% predicted) & $0.961(0.938-0.984)$ & 0.001 & $0.974(0.947-1.002)$ & 0.064 \\
\hline Age-adjusted CCl & $1.204(0.990-1.465)$ & 0.063 & & \\
\hline VATS (vs. open) & $0.253(0.123-0.519)$ & $<0.001$ & $0.557(0.241-1.286)$ & 0.171 \\
\hline \multicolumn{5}{|l|}{ Operation } \\
\hline Sublobar resection & 1 & & 1 & \\
\hline Lobectomy & $1.654(0.392-6.983)$ & 0.494 & $0.598(0.130-2.760)$ & 0.510 \\
\hline Extended resection & $8.642(1.830-40.803)$ & 0.006 & $0.982(0.164-5.876)$ & 0.985 \\
\hline \multicolumn{5}{|l|}{ Pathology } \\
\hline $\mathrm{SqCC}$ & 1 & & 1 & \\
\hline Adenocarcinoma & $0.193(0.097-0.382)$ & $<0.001$ & $0.539(0.222-1.308)$ & 0.172 \\
\hline Other NSCLC & $0.149(0.020-1.114)$ & 0.064 & $0.349(0.043-2.817)$ & 0.323 \\
\hline \multicolumn{5}{|l|}{ Pathologic stage } \\
\hline I & 1 & & 1 & \\
\hline II & $3.438(1.204-9.820)$ & 0.021 & $2.205(0.669-7.268)$ & 0.194 \\
\hline III & $12.916(5.488-30.398)$ & $<0.001$ & $13.986(4.293-45.568)$ & $<0.001$ \\
\hline Postoperative complication & $2.337(1.177-4.641)$ & 0.015 & $1.695(0.784-3.665)$ & 0.180 \\
\hline Adjuvant treatment & $2.265(1.166-4.403)$ & 0.016 & $0.516(0.203-1.312)$ & 0.165 \\
\hline
\end{tabular}

$\mathrm{Cl}$, confidence interval; FEV1, forced expiratory volume in 1 second; DLCO, diffusing capacity of lung for carbon monoxide; CCl, Charlson comorbidity index; VATS, video-assisted thoracoscopic surgery; SqCC, squamous cell carcinoma; NSCLC, non-small cell lung cancer. 
Table 5. Prognostic factors for overall survival using a Cox regression model in high-risk patients

\begin{tabular}{|c|c|c|c|c|}
\hline \multirow{2}{*}{ Variable } & \multicolumn{2}{|c|}{ Univariable } & \multicolumn{2}{|c|}{ Multivariable } \\
\hline & Hazard ratio $(95 \% \mathrm{Cl})$ & p-value & Hazard ratio $(95 \% \mathrm{Cl})$ & $\mathrm{p}$-value \\
\hline Age (yr) & $0.958(0.906-1.013)$ & 0.130 & & \\
\hline Female (vs. male) & $0.171(0.023-1.284)$ & 0.086 & $0.280(0.036-2.168)$ & 0.223 \\
\hline \multicolumn{5}{|l|}{ Smoking } \\
\hline Nonsmoker & 1 & & - & \\
\hline Ex-smoker & $0.885(0.359-2.182)$ & 0.791 & - & \\
\hline Current smoker & $0.429(0.094-1.958)$ & 0.274 & - & \\
\hline FEV1 (\% predicted) & $0.997(0.977-1.017)$ & 0.735 & - & \\
\hline DLCO (\% predicted) & $0.954(0.907-1.003)$ & 0.065 & $0.969(0.919-1.021)$ & 0.242 \\
\hline Age-adjusted CCI & $0.891(0.665-1.194)$ & 0.440 & - & \\
\hline VATS (vs. open) & $1.166(0.489-2.780)$ & 0.728 & - & \\
\hline \multicolumn{5}{|l|}{ Operation } \\
\hline Sublobar resection & 1 & & - & \\
\hline Lobectomy & $0.981(0.326-2.959)$ & 0.974 & - & \\
\hline Extended resection & $0.917(0.168-5.020)$ & 0.921 & - & \\
\hline \multicolumn{5}{|l|}{ Pathology } \\
\hline $\mathrm{SqCC}$ & 1 & & - & \\
\hline Adenocarcinoma & $0.867(0.354-2.123)$ & 0.755 & - & \\
\hline Other NSCLC & $1.233(0.159-9.547)$ & 0.841 & - & \\
\hline \multicolumn{5}{|l|}{ Pathologic stage } \\
\hline 1 & 1 & & - & \\
\hline II & $1.164(0.370-3.663)$ & 0.795 & - & \\
\hline III & $2.230(0.817-6.086)$ & 0.118 & - & \\
\hline Postoperative complication & $5.539(1.848-16.603)$ & 0.002 & $4.255(1.383-13.097)$ & 0.012 \\
\hline Adjuvant treatment & $1.454(0.526-4.017)$ & 0.470 & - & \\
\hline
\end{tabular}

$\mathrm{Cl}$, confidence interval; FEV1, forced expiratory volume in 1 second; DLCO, diffusing capacity of lung for carbon monoxide; CCl, Charlson comorbidity index; VATS, video-assisted thoracoscopic surgery; SqCC, squamous cell carcinoma; NSCLC, non-small cell lung cancer.

in recurrence between $\mathrm{HR}$ patients with PCs and SR patients with or without PCs $(\mathrm{p}=0.502$ and $\mathrm{p}=0.757$, respectively) (Fig. 3B).

\section{Risk factors for postoperative complications in high-risk patients}

Risk factors for PCs were analyzed using binary logistic regression analysis in the $\mathrm{HR}$ group. In the multivariable analysis, lower DLCO and lobectomy were identified as significant risk factors for PCs (Table 6).

\section{Discussion}

In the present study, the incidence of PCs and 90-day mortality rate was $50.6 \%$ and $10.4 \%$, respectively, in HR patients; the rates of both of these outcomes were significantly higher in HR patients than in SR patients. However, HR status was not an independent prognostic factor in the multivariable Cox regression analysis of all patients. PCs were the only significant prognostic factor in the multi- variable Cox regression analysis of HR patients. HR patients with PCs had worse overall survival, but a similar recurrence rate, compared to SR patients. HR patients without PCs had a survival rate similar to that of SR patients. Undergoing lobectomy and having a lower DLCO were associated with PCs in HR patients.

The criteria for identifying HR patients were adopted from the ACOSOG Z4099 trial, wherein the prognosis of sublobar resection and SBRT were compared in HR patients with operable NSCLC [13]. The criteria for enrollment of the trial defined lung cancer patients as "HR" for surgery. The criteria (definition of "HR" status) were determined by expert consensus and with audit verification, rather than being based on empirical evidence. As demonstrated by Puri et al. [17], who safely performed lobectomy in HR lung cancer patients, disagreement can exist regarding the definition of HR for surgery. In this study, despite the operative risks, lobectomy was the most frequently performed procedure in the HR group (71.4\%), which might be related to the high prevalence of SqCC and advanced stage in HR patients. SqCC comprised $54.5 \%$ of 
A

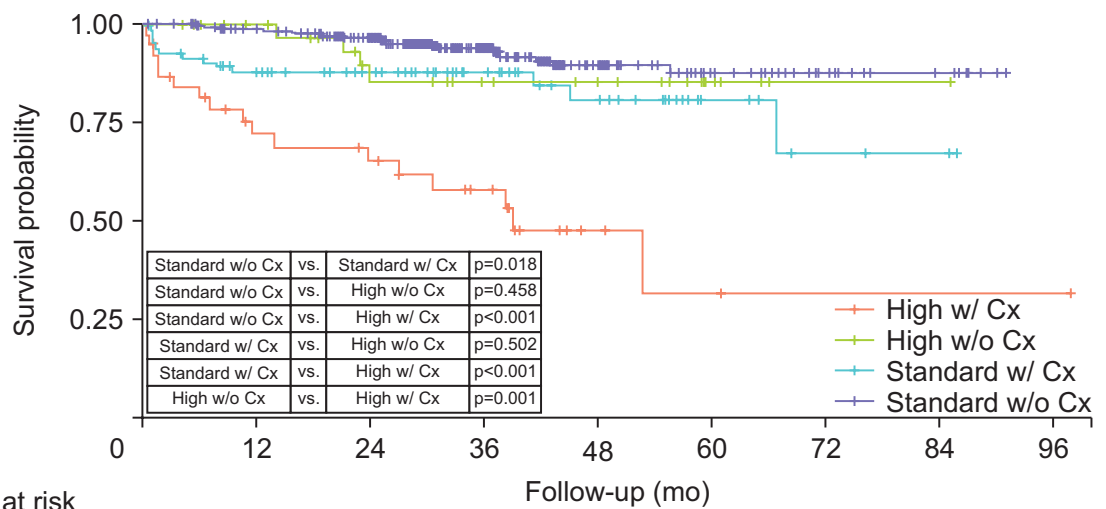

\begin{tabular}{rrrrrrrrrr} 
No. at risk & \multicolumn{8}{c}{ Follow-up (mo) } \\
High w/ Cx & 39 & 22 & 19 & 13 & 4 & 2 & 1 & 1 & 1 \\
High w/o CX & 38 & 32 & 22 & 16 & 12 & 5 & 1 & 1 & 0 \\
Standard w/ CX & 84 & 68 & 56 & 36 & 22 & 9 & 4 & 3 & 0 \\
Standard w/o Cx & 310 & 290 & 239 & 134 & 71 & 32 & 15 & 8 & 0
\end{tabular}

B

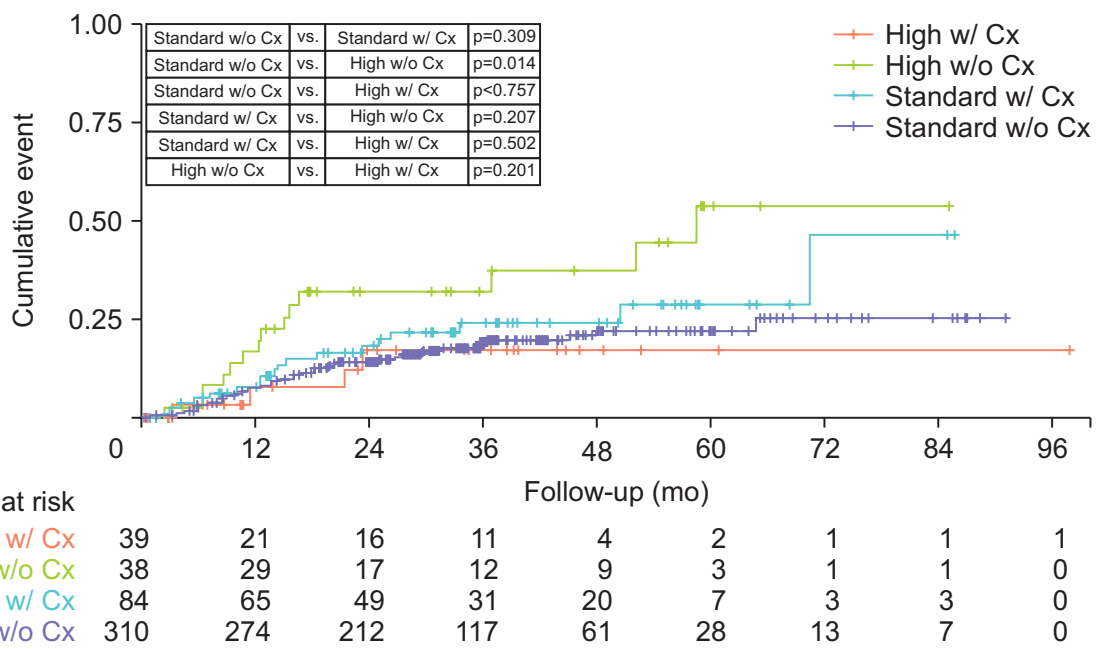

Fig. 3. (A) Overall survival and (B) cumulative incidence of recurrence according to risk group and postoperative complications. w/, with; w/o, without; Cx, complication.

histological cancer subtypes in the HR group. SqCCs are often centrally located and frequently need lobectomy for R0 resection. In addition, $42.9 \%$ of HR patients had NSCLC of stage II or greater. In the multivariable Cox model of all patients, lobectomy and HR were not independent prognostic factors. Taylor et al. [18] analyzed 1,259 consecutive patients who underwent lobectomy for NSCLC, and classified 206 patients as HR according to the ASCOG Z 4099 criteria. In their study, HR status was not an independent prognostic factor for major morbidity or survival [18].

Lugg et al. [19] analyzed 670 patients who underwent lung resection to evaluate the long-term impact of postoperative pulmonary complications. Eighty-six patients (13\%) had PCs. Compared to patients without PCs, more patients with PCs died from postoperative pulmonary complications $(1 \%$ versus $10 \%, \mathrm{p}<0.001)$ and non-cancer-related causes when excluding postoperative deaths (5\% versus $11 \%, \mathrm{p}=0.020$ ). The presence of PCs, staging, age, and rates of readmission within 30 days of surgery were independent risk factors for late death in their study. In their study analyzing 129,893 patients who underwent surgery for NSCLC from the National Cancer Database, Puri et al. [20] additionally demonstrated that the rate of readmission within 30 days of surgery was an independent prognostic factor for long-term survival.

In our cohort, the presence of PCs was an independent prognostic factor in multivariable Cox analysis of all patients and in HR patients, unlike in SR patients. Pulmonary complications, which predominantly occurred in HR patients, comprised $94.8 \%$ (37 of 39) of the total PCs in HR patients. These results suggest that HR patients are more vulnerable to PCs and that PCs have a significant impact on survival. Furthermore, HR patients with PCs had poorer overall survival, but a similar recurrence rate, compared to SR patients. These suggest that HR patients with PCs died of treatment-related or non-cancer-related causes be- 
Table 6. Risk factors for postoperative complications using a logistic regression model in high-risk patients

\begin{tabular}{|c|c|c|c|c|}
\hline \multirow{2}{*}{ Variable } & \multicolumn{2}{|c|}{ Univariable } & \multicolumn{2}{|c|}{ Multivariable } \\
\hline & OR $(95 \% \mathrm{Cl})$ & p-value & OR $(95 \% \mathrm{Cl})$ & p-value \\
\hline Age $(y r)$ & $0.097(0.914-1.043)$ & 0.504 & - & \\
\hline Female (vs. male) & $0.320(0.080-1.067)$ & 0.076 & $0.258(0.058-0.977)$ & 0.054 \\
\hline Body mass index $\left(\mathrm{kg} / \mathrm{m}^{2}\right)$ & $0.904(0.763-1.059)$ & 0.225 & - & \\
\hline \multicolumn{5}{|l|}{ Smoking } \\
\hline Nonsmoker & 1 & & - & \\
\hline Ex-smoker & $1.476(0.543-4.080)$ & 0.446 & - & \\
\hline Current smoker & $2.769(0.788-10.760)$ & 0.121 & - & \\
\hline Age-adjusted CCI & $1(0.729-1.371)$ & 1 & - & \\
\hline FEV1 (\% predicted) & $1.002(0.980-1.025)$ & 0.812 & - & \\
\hline DLCO (\% predicted) & $0.957(0.907-0.997)$ & 0.067 & $0.951(0.898-0.994)$ & 0.049 \\
\hline VATS (vs. open) & $1.600(0.649-4.007)$ & 0.309 & - & \\
\hline \multicolumn{5}{|l|}{ Operation } \\
\hline Sublobar resection & 1 & & 1 & \\
\hline Lobectomy & $3(0.934-10.760)$ & 0.073 & $4.407(1.239-17.813)$ & 0.027 \\
\hline Extended resection & $0.333(0.015-2.787)$ & 0.364 & $0.352(0.015-3.168)$ & 0.400 \\
\hline \multicolumn{5}{|l|}{ Pathologic stage } \\
\hline I & 1 & & - & \\
\hline II & $1.125(0.364-3.515)$ & 0.837 & - & \\
\hline III & $1(0.314-3.182)$ & 1 & - & \\
\hline
\end{tabular}

$\mathrm{OR}$, odds ratio; $\mathrm{Cl}$, confidence interval; FEV1, forced expiratory volume in 1 second; DLCO, diffusing capacity of lung for carbon monxide; CCl, Charlson comorbidity index; VATS, video-assisted thoracoscopic surgery.

fore experiencing recurrence.

These results suggest that efforts to reduce PCs are critical when performing surgery in HR patients with operable NSCLC. Patients who need lobectomy rather than sublobar resection, and who have lower DLCO, should be managed with particular care, given that the risk of PCs may be higher in such patients. A careful preoperative assessment should be performed, including exercise and cardiopulmonary tests. Patients' comorbidities and their modifiable risk factors should be assessed meticulously, and management decisions should be made by multidisciplinary teams [21]. Emerging evidence suggests that perioperative rehabilitation and enhanced recovery after surgery (ERAS) protocols may reduce PCs after lung cancer surgery [22-24]. HR patients in particular may benefit from these approaches; however, further large-scale studies are needed to elucidate the benefits of ERAS protocols.

First, this study has inherent biases as we used retrospective data. Additionally, this was a single-center study with a small sample size, which may have caused type II error in the analyses. Second, patients with worse outcomes and more significant morbidities were not included in our study, as such patients would have undergone non-surgical treatment such as SBRT. HR patients who underwent surgical treatment were carefully selected, and our HR cohort is not representative of all HR patients with NSCLC. Therefore, we cannot exclude the possibility of selection bias, and our results are not generalizable to all HR patients with NSCLC. The overall postoperative survival of HR patients with NSCLC was affected more by PCs than by any other prognostic factor. Care should be taken to reduce PCs, especially in HR patients with NSCLC.

\section{Conflict of interest}

No potential conflict of interest relevant to this article was reported.

\section{ORCID}

Seungwook Lee: https://orcid.org/0000-0003-1616-3595 Md Roknuggaman: https://orcid.org/0000-0003-1817-655X Jung A Son: https://orcid.org/0000-0002-0736-1226 Seungji Hyun: https://orcid.org/0000-0002-2578-3510 Joonho Jung: https://orcid.org/0000-0002-1078-8116 Seokjin Haam: https://orcid.org/0000-0002-0403-2216 Woo Sik Yu: https://orcid.org/0000-0002-5100-9131 


\section{References}

1. Hong S, Won YJ, Park YR, et al. Cancer statistics in Korea: incidence, mortality, survival, and prevalence in 2017. Cancer Res Treat 2020;52:335-50

2. Torre LA, Bray F, Siegel RL, Ferlay J, Lortet-Tieulent J, Jemal A. Global cancer statistics, 2012. CA Cancer J Clin 2015;65:87-108.

3. Herbst RS, Heymach JV, Lippman SM. Lung cancer. N Engl J Med 2008;359:1367-80.

4. National Comprehensive Cancer Network. NCCN guidelines for non-small cell lung cancer, version 5.2021 [Internet]. Plymouth Meeting (PA): National Comprehensive Cancer Network; 2021 [cited 2021 Aug 18]. Available from: https://www.nccn.org/professionals/ physician_gls/pdf/nscl.pdf.

5. Chansky K, Sculier JP, Crowley JJ, et al. The International Association for the Study of Lung Cancer Staging Project: prognostic factors and pathologic TNM stage in surgically managed non-small cell lung cancer. J Thorac Oncol 2009;4:792-801.

6. Yang CC, Fong Y, Lin LC, et al. The age-adjusted Charlson comorbidity index is a better predictor of survival in operated lung cancer patients than the Charlson and Elixhauser comorbidity indices. Eur J Cardiothorac Surg 2018;53:235-40.

7. Birim O, Kappetein AP, Bogers AJ. Charlson comorbidity index as a predictor of long-term outcome after surgery for nonsmall cell lung cancer. Eur J Cardiothorac Surg 2005;28:759-62.

8. Luchtenborg M, Jakobsen E, Krasnik M, Linklater KM, Mellemgaard A, Moller H. The effect of comorbidity on stage-specific survival in resected non-small cell lung cancer patients. Eur J Cancer 2012;48:3386-95.

9. Tammemagi CM, Neslund-Dudas C, Simoff M, Kvale P. In lung cancer patients, age, race-ethnicity, gender and smoking predict adverse comorbidity, which in turn predicts treatment and survival. J Clin Epidemiol 2004;57:597-609.

10. Donington J, Ferguson M, Mazzone P, et al. American College of Chest Physicians and Society of Thoracic Surgeons consensus statement for evaluation and management for high-risk patients with stage I non-small cell lung cancer. Chest 2012;142:1620-35.

11. Colice GL, Shafazand S, Griffin JP, Keenan R, Bolliger CT; American College of Chest Physicians. Physiologic evaluation of the patient with lung cancer being considered for resectional surgery: ACCP evidenced-based clinical practice guidelines (2nd edition). Chest 2007;132(3 Suppl):161S-177S.

12. Donahoe LL, de Valence M, Atenafu EG, et al. High risk for thoracotomy but not thoracoscopic lobectomy. Ann Thorac Surg 2017;
103:1730-5.

13. Fernando HC, Timmerman R. American College of Surgeons Oncology Group Z4099/Radiation Therapy Oncology Group 1021: a randomized study of sublobar resection compared with stereotactic body radiotherapy for high-risk stage I non-small cell lung cancer. J Thorac Cardiovasc Surg 2012;144:S35-8.

14. Charlson ME, Pompei P, Ales KL, MacKenzie CR. A new method of classifying prognostic comorbidity in longitudinal studies: development and validation. J Chronic Dis 1987;40:373-83.

15. Goldstraw P, Chansky K, Crowley J, et al. The IASLC Lung Cancer Staging Project: proposals for revision of the TNM stage groupings in the forthcoming (eighth) edition of the TNM classification for lung cancer. J Thorac Oncol 2016;11:39-51.

16. Clavien PA, Barkun J, de Oliveira ML, et al. The Clavien-Dindo classification of surgical complications: five-year experience. Ann Surg 2009;250:187-96.

17. Puri V, Crabtree TD, Bell JM, et al. National cooperative group trials of "high-risk" patients with lung cancer: are they truly "high-risk"? Ann Thorac Surg 2014;97:1678-85.

18. Taylor MD, LaPar DJ, Isbell JM, Kozower BD, Lau CL, Jones DR. Marginal pulmonary function should not preclude lobectomy in selected patients with non-small cell lung cancer. J Thorac Cardiovasc Surg 2014;147:738-46.

19. Lugg ST, Agostini PJ, Tikka T, et al. Long-term impact of developing a postoperative pulmonary complication after lung surgery. Thorax 2016;71:171-6.

20. Puri V, Patel AP, Crabtree TD, et al. Unexpected readmission after lung cancer surgery: a benign event? J Thorac Cardiovasc Surg 2015;150:1496-505.

21. Geraci TC, $\mathrm{Ng}$ T. When is it safe to operate for lung cancer?: selection of fiscally responsible cardiopulmonary function tests for limited resection (wedge resection and segmentectomy), standard lobectomy, sleeve lobectomy, and pneumonectomy. Thorac Surg Clin 2021;31: 255-63.

22. Bibo L, Goldblatt J, Merry C. Does preoperative pulmonary rehabilitation/physiotherapy improve patient outcomes following lung resection? Interact Cardiovasc Thorac Surg 2021;32:933-7.

23. Kong M, Zheng H, Ding L, et al. Perioperative pulmonary rehabilitation training (PPRT) can reduce the cost of medical resources in patients undergoing thoracoscopic lung cancer resection: a retrospective study. Ann Palliat Med 2021;10:4418-27.

24. Wang X, Wang N, Wang X, et al. Application value of goal-directed fluid therapy with ERAS in patients undergoing radical lung cancer surgery. Am J Transl Res 2021;13:8186-92. 